\title{
Nanocomposite Poly(lactic acid)/sepiolite with Improved Mechanical and Biofilms Formation Properties
}

\author{
ORIANA PALMA CALABOKIS ${ }^{1 *}$, ROSESTELA PERERA ${ }^{2}$, CARMEN ROSALES ${ }^{2}$, \\ YAMID NUÑEZ ${ }^{1}$, JAIRO SEGURA ${ }^{3}$, ALVARO ARRIETA ${ }^{4}$ \\ ${ }^{1}$ Postgraduate Program of Mechanical and Materials Engineering - Federal University of Technology of Paraná, Curitiba, \\ Brazil \\ ${ }^{2}$ Department of Mechanics - Simón Bolívar University, Caracas, Venezuela \\ ${ }^{3}$ Institute for Sciences and Labor Training of La Sabana - ICSA - Sincelejo, Colombia \\ ${ }^{4}$ Department of Biology and Chemistry, University of Sucre, Sincelejo, Colombia
}

\begin{abstract}
Nanocomposites of poly(lactic acid) with sepiolite needles (5 wt.\%) were evaluated in terms of the mechanical and biofilm formation properties. The nanocomposite exhibited higher values of the Young's modulus and tensile strength at break compared to the PLA, without detriment in the percent elongation at break. These improvements were related to the high aspect ratio of the nanoclay, the polymer-clay interactions, and the degree of dispersion. The growth of Pseudomonas aeruginosa on the surface of the PLA and NPLA materials was promoted in different conditions. Medium with different concentration of nutrients were used and also were compared the effect of the medium physical state (solid or liquid medium). Biofilms were formed in all the conditions. However, the nanocomposite presented a higher area coverage of microorganisms on its surface, possibly due to the positive effects of the nanoclay on the bacterial adhesion.
\end{abstract}

Keywords: poly(lactic acid), sSepiolite, nanocomposite, Pseudomonas aeruginosa

\section{Introduction}

In recent years, research on poly(lactic acid) (PLA) has gained increasingly interest due to its biodegradable, biocompatible and thermoplastic character. It is one of the most widely used biopolymers currently synthesized from the bacterial fermentation of different starches [1]. It is an aliphatic polyester that has gained increasingly attractive environmental, biomedical, agricultural, and packing applications [2]. In order to improve mechanical properties, such as stiffness and Young's modulus, thermal properties and permeability to gases or liquids, nanoclays have been incorporated into poly(lactic acid). The most frequently nanoclays studied include: sepiolite, montmorillonite (MMT), synthetic fluorohectorite (SOM) and calcium nanocarbonate (NCC) [3-13].

Fukushima et al. [5] found that PLA nanocomposites with sepiolite (5 wt.\%), had good nanoclay dispersion and few aggregates without the need for chemical modification of the sepiolite surface, unlike other nanoclays such as montmorillonite (MMT) and synthetic fluorohectorite (SOM). Russo et al. [7] reported good dispersion up to 3 wt.\% sepiolite contents, while Fukushima et al. [3] confirmed acceptable dispersion up to $5 \mathrm{wt} . \%$. The good dispersion of the sepiolite needles ( $5 \mathrm{wt} . \%)$ without surface chemical modification was attributed to the hydrogen bonds formed between the carbonyl groups of the PLA and the hydroxyl groups of the sepiolite.

Sabzi et al. [6] evaluated the mechanical properties of PLA 3251D NatureWorks® nanocomposites made with sepiolite and calcium nanocarbonate (NCC) at contents of 1, 3, 5 and $10 \mathrm{wt} . \%$. All the nanocomposites presented tensile strengths, deformations to fracture and Young's modulus higher than those of the PLA pure (without load). At nanoclay contents higher than $3 \mathrm{wt} \%$, the mechanical properties began to be deteriorated due to the lower dispersion of the loads. Also, Núñez et al. [4, 8] and Rosales et al. [9] evaluated the effect of adding sepiolite in polymer blends of PLA (matrix) with other polymers such as low-density polyethylene and polypropylene, using compatibilizers. They found good compatibility, due to the favorable polymer-clay interactions between the silanol groups of sepiolite and

*email: calabokis@alunos.utfpr.edu.br 
the carbonyls of the compatibilizer agents. Furthermore, when the sepiolite was added to the polymer blends, materials with a higher yield stress, tensile strength and higher Young's modulus were obtained compared to their counterparts (PLA blends without nanoclay). However, other properties such as elongation at break and toughness were deteriorated $[4,8,9]$.

PLA is a biopolymer that has different degradation mechanisms depending on environmental conditions [1]. Fukushima et al. [14] developed a study relates to the biodegradation of the PLA nanocomposites with sepiolite. They placed nanocomposite films in direct contact with compost under aerobic conditions. They verified that the presence of sepiolite effectively delayed the degradation of PLA evidenced by a reduced amount of mass loss and less reduction in molecular weight. Other relevant research was carried out by Walczak et al. [15] which studied the biodegradation of PLA under three different conditions: lake water, compost, and soil. These researchers determined that biodegradation occurs by hydrolytic activity of microorganisms in the three environments, being more accelerated in the compost. However, they found that biodegradation occurs through different mechanisms in lake water, being the most favored the biofilm formation [15].

Biofilms are understood as viscous layers established by microorganisms that cover solid surfaces, consisting of water, extracellular polymeric substances, microorganisms and trapped organic and inorganic particles. These structures can cause biodeterioration or biodegradation [16]. The first term refers to the incomplete degradation, especially the loss of the properties and characteristics of the material that serves as the substrate. On the other hand, biodegradation is the molecular detriment that occurs due to the activity of microorganisms and / or their enzymes [17-19]. In the present work, the biofilm formation of the Pseudomonas aeruginosa on the PLA and on the nanocomposite of PLA with sepiolite as a possible degradation mechanism were studied. In addition, the effect of the nanoclay and the thermal history of the PLA on the tensile mechanical properties was addressed.

\section{Materials and methods}

\subsection{Materials}

The poly (lactic acid) (PLA) is a commercial grade (PLA 2002D extrusion grade) manufactured by NatureWorks®. Its physical, chemical, and mechanical properties are in the datasheet [20]. Sepiolite with the commercial name Pangel CDT71 supplied by Tolsa, was the nanofiller used. The chemical formula is $\mathrm{Si}_{6} \mathrm{Mg}_{4} \mathrm{O}_{156}\left(\mathrm{H}_{2} \mathrm{O}\right)$. It is a clay modified with $2 \%$ vinyl (trimethoxy) silane and its properties are available in the datasheet [21].

\subsection{Preparation of the samples}

The PLA pellets and the sepiolite in powder, were previously dried to eliminate the humidity that could promote the degradative process of the PLA during mixing. The PLA pellets were dried for $90 \mathrm{~h}$ at $52^{\circ} \mathrm{C}$ in a vacuum oven $(20 \mathrm{mmHg})$. The sepiolite powder was dried for $2 \mathrm{~h}$ at $120^{\circ} \mathrm{C}$ in a forced air convection oven.

The nanocomposite with composition of $5 \%$ by weight (nPLA) was made by melt mixing using a Co-rotating twin-screw extruder (Berstorff model ECS-25). The PLA pellets were added through the feed hopper of the extruder and the sepiolite powder was fed through the second port. The temperature profile started at $160^{\circ} \mathrm{C}$ in the feeding zone up to $175^{\circ} \mathrm{C}$ at the nozzle. The screw rotation frequency was set at $100 \mathrm{rpm}$. The extrudate cooling was accomplished with water and immediately pelletized.

The actual amount of sepiolite incorporated into the nanocomposite (nPLA) was determined by calcination. For this, samples of the nanocomposite (pellets prepared by melt mixing) were placed in a refractory furnace, which were calcined for 4 consecutive days at a maximum temperature of $700^{\circ} \mathrm{C}$. This temperature was chosen for ensuring the complete decomposition of the polymer. The actual amount of clay was determined by differences in the mass after each day of calcination. 


\subsection{Tensile properties}

Type I specimens were manufactured according to ASTM D638 standard by injection molding under the conditions of: clamping force of $650 \mathrm{kN}$, Nozzle temperature of $190^{\circ} \mathrm{C}$, injection pressure of $60 \mathrm{MPa}$, and injection time of $7 \mathrm{~s}$. The values of Young's modulus $(\mathrm{E})$, tensile strength at yield $(\sigma \mathrm{y})$, percent elongation at yield $(\varepsilon Y)$, tensile strength at break $(\sigma b)$ and percent elongation at break $(\varepsilon b)$ were estimated.

\subsection{Biofilm formation}

The biodegradation of PLA and its nanocomposite (nPLA) was studied by the biofilm formation mechanism in both solid (Figure 1a) and liquid medium (Figure 1b) in coupons cut from thin films. In both cases, $100 \mu \mathrm{L}$ of bacterial culture (Pseudomonas aeruginosa) were used. Thin films were made by compression molding using a hydraulic press at $175^{\circ} \mathrm{C}$. All the material (extruded pellets) was previously dried in a vacuum oven $(20 \mathrm{mmHg})$ at $52^{\circ} \mathrm{C}$ for $24 \mathrm{~h}$. Before the tests, all the coupons were previously sterilized for one hour in a cabin under UV radiation.

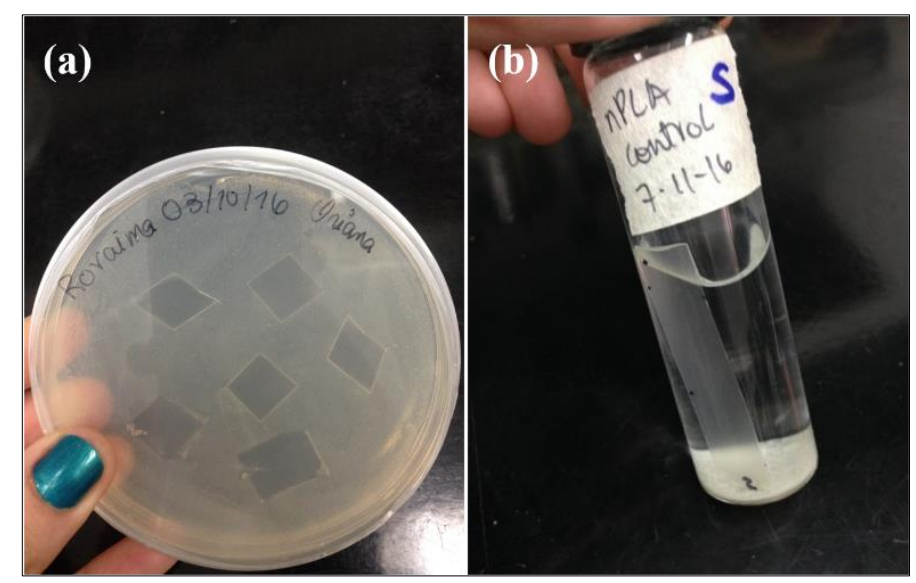

Figure 1. Biofilm formation (Pseudomonas aeruginosa) in polymer coupons placed in solid agar (a) and in liquid medium (b)

For bacterial growth in the solid medium, Petri dishes were filled with solid agar supplemented with rich and low nutrient medium. In the case of nutrient-low agar, it was prepared following the composition suggested by Pardee et al. [23]. The agar supplemented with nutrient-rich medium was made with a formulation patented by the ThermoFisher $®$. Bacteria culture was spread on the solid agar using a Drigalsky spatula and afterwards, square coupons $\left(1 \mathrm{~cm}^{2}\right)$ of the polymer films were placed on it (Figure 1a). Petri dishes were properly sealed and kept at $37^{\circ} \mathrm{C}$ in an incubator. Three random coupons were removed at the times of 24, 48, 72, 168 and $336 \mathrm{~h}$.

The bacterial growth in the liquid medium were carried out only in nutrient-low medium or basal medium. For these tests, rectangular polymer coupons (strips coupons) were used with dimension of 5 $\mathrm{x} 1 \mathrm{~cm}$ (Figure 1b). In this case, the bacterial culture was added directly to the liquid medium. In this case, the strips coupons were submerged for 30 days, kept at $37^{\circ} \mathrm{C}$ in an incubator.

Once the coupons were removed from the medium, a drop of violet crystal solution (1\%) was placed in contact with each coupon for $15 \mathrm{~min}$ with the purpose of staining the microorganisms, as suggested by O'toole and Korter [22]. Afterward, the bacterial colonies and biofilms were observed under the light microscope at $60 \mathrm{X}$ magnification.

\section{Results and discussions}

In order to determine the actual amount of sepiolite content in the nanocomposite samples made by extrusion, the calcination procedure was performed. The results are reported in Table 1 and they confirm that complete decomposition of the polymeric material was achieved on the second day of calcination. 
From the second day there were no significant variations in the mass. Therefore, it is understood that a third day of this procedure is unnecessary. In all the calcined samples, the actual sepiolite content exceeded $75 \%$ of the theoretical content (5 wt. \%).

Table 1. Real composition of sepiolite determined by calcination

\begin{tabular}{|c|c|c|c|}
\hline & Day 1 & Day 2 & Day 3 \\
\hline & \multicolumn{3}{|c|}{ Real composition (wt.\%) } \\
\hline nPLA & 4.509 & 4.489 & 4.484 \\
\hline
\end{tabular}

Poly(lactic acid) is a biodegradable polyester characterized by its low ductility and low impact resistance, but with high rigidity. The mechanical properties of PLA depend on its degree of crystallinity, chemical structure, ratio of enantiomers, molecular weight, formulation of the material (presence of fillers, dispersed phases, plasticizers, etc.) and its processing conditions [11]. In the present investigation, the effect of the addition of the sepiolite nanoclay on the tensile behavior was studied following the ASTM D638 standard. The results are reported in Table 2.

Table 2. Average values of Young's modulus $(\mathrm{E})$, tensile strength at yield $\left(\sigma_{\mathrm{y}}\right)$, percent elongation at yield $\left(\varepsilon_{\mathrm{Y}}\right)$, tensile strength at break $\left(\sigma_{\mathrm{b}}\right)$ and percent elongation at break $\left(\varepsilon_{\mathrm{b}}\right)$

\begin{tabular}{|c|c|c|c|c|c|}
\hline Material & $\mathrm{E}(\mathrm{MPa})$ & $\sigma_{\mathrm{y}}(\mathrm{MPa})$ & $\varepsilon_{\mathrm{y}}(\%)$ & $\sigma_{\mathrm{b}}(\mathrm{MPa})$ & $\varepsilon_{\mathrm{b}}(\%)$ \\
\hline PLA (raw material) & $2300 \pm 345$ & - & - & $57 \pm 0$ & $3.3 \pm 0,1$ \\
\hline PLA (extruded) & $2420 \pm 250$ & - & - & $61 \pm 1$ & $3.3 \pm 0,1$ \\
\hline nPLA & $2940 \pm 405$ & - & - & $66 \pm 2$ & $3.1 \pm 0,1$ \\
\hline
\end{tabular}

As listed in Table 2, two types of PLA were tested with the purpose of evaluating the effect of the thermal history due to degradation during the processing, in the mechanical properties. The PLA (raw material) specimens were manufactured by injection molding the PLA pellets directly purchased from the manufacturer. The pellets were not dried prior to injection. Therefore, the thermal history of the PLA (raw material) was shorter compared to the other. The PLA (extruded) specimens were subjected to a longer thermal history: the raw material was previously extruded and pelletizer, then they were dried for $24 \mathrm{~h}$ at $52^{\circ} \mathrm{C}$ in vacuum before being fed into the injection machine. The stress-strain curve of both materials is presented in Figure 2. The test specimens of both materials, after being tested, exhibited flow lines in the direction transverse to the tensile test. The literature reports that the PLA has the mechanism of plastic deformation known as crazing, therefore those flow lines in the tensile samples were identified as crazes $[1,4,8]$.

\subsection{Mechanical properties}

The PLA (extruded) samples exhibited similar mechanical properties as the PLA (raw material), despite the different thermal histories. Taubner et al. [10] compared the PLA previously conditioned with relative humidity of $65 \%$ and the PLA pre-dried, both processed in an internal mixer. The conditioned PLA had more significant reductions in molecular weight, viscosity, and mechanical properties. Those negative effects were due to the catalytic effect of moisture in the degradation reactions by hydrolysis at the processing temperatures recommended by the manufacturer $\left(210^{\circ} \mathrm{C}\right)$. The properties at the point of rupture of the conditioned material, decreased with the decrease in molecular weight, because the shorter chains do not allow the necessary number of molecular entanglements to be formed. Rosales et al., [9] also found that the PLA processing reduces the thermo-mechanical stability of the polymer and causes an abrupt decrease in the viscosimetric molecular weight, which affects the mechanical properties. The thermal history in the PLA processing favors its degradation, which can occur due to chain cleavage reactions, depolymerization, oxidative and hydrolytic degradation, thermomechanical degradation mechanisms, among others that harm the physical and mechanical properties of 
the PLA [1]. On the one hand, the PLA (extruded) had a greater thermal history, however on the other, the PLA (raw material) probably underwent hydrolytic degradation during injection because it was not dried previously. Both factors may explain the similar results in the mechanical properties of both materials. This result confirmed the imperative drying of the PLA prior to its processing.

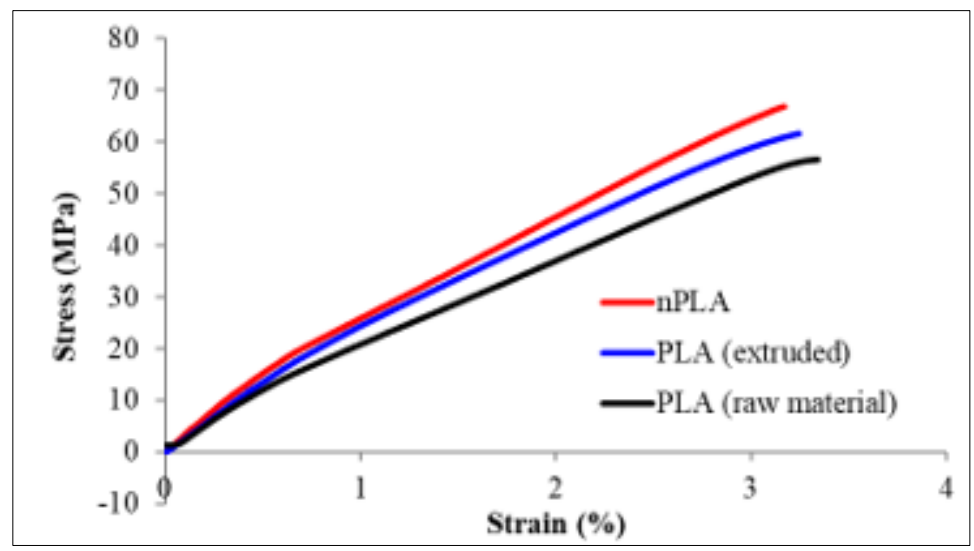

Figure 2. Stress-strain curves of PLA and its nanocomposite (nPLA)

In Figure 2 and Table 2 are exhibited the stress-strain curve and the mechanical properties of the PLA-Sepiolite nanocomposite (nPLA). The average value of Young's modulus of the nPLA exceeded the modulus of the PLA (extruded) by approximately 20\%. The increase in the modulus of the nanocomposite compared to the original properties of the matrix as the clay content increases, has been evaluated by other researchers [4-6, 11, 13]. Furthermore, the tensile strength at break of the nanocomposite was slightly higher to the average value of the PLA (extruded). The increase in stiffness has been explained mainly by three factors: the aspect ratio of the clay, the polymer-clay interactions, and the degree of dispersion. The sepiolite, due to its acicular structure, has a high aspect ratio and a high surface area value, therefore it allows a more efficient stress transfer [11]. On the other hand, polymer-clay interactions improve stress transfer in the interface, having an effective increase in the reinforcement level [9].

Liu et al. [12] found specific interactions between silanol groups of the sepiolite and the ester groups of the PLA. Furthermore, Moazeni et al. [11] modified the surface of the sepiolite, finding improvements in modulus and strength at break compared to nanocomposites with unmodified sepiolite. The homogeneous degree of dispersion increases the stiffness of the nanocomposites since it reduces the possibility of particle agglomerates, which cause premature failure of the material due to stress concentration [13]. The increase in the average modulus of the PLA nanocomposite with sepiolite, also it has been justified by the lower degradation of the nanocomposite compared to the pure material when processed [4].

Despite the increases in the stiffness of the reinforced material (nPLA), the average of the percent elongation at break did not vary considerably compared to the PLA (extruded) due to the scatter of these results. Some researchers $[6,7]$ have obtained a decrease in the elongation value at break in PLA with sepiolite content of $5 \mathrm{wt} . \%$ or more. According to they, this is a consequence of the higher stiffness modulus of the clay, which constrains the deformation or relaxation of the polymer matrix, when the forces are applied to the composite material. Therefore, the movements of the PLA chains are restricted by the presence of the sepiolite needles [11].

\subsection{Biofilm formation}

The Pseudomonas aeruginosa is an elongated environmental bacterium, like bacilli, and is a natural habitant of soils and water reservoirs. The strain used in the present investigation was found in Roraima, isolated by the professor Paula Suárez, from the Simón Bolívar University. It is one of the species that colonize various environments, through the formation of structures known as biofilms, obtained in 
drains, pipes, food containers, contact lenses, even catheters and other devices within the body [16].

In this investigation, biofilm formation was evaluated as a biodegradation mechanism in the square coupons of films of PLA and nPLA materials placed on solid agar supplemented with a basal (nutrientlow) medium. This medium was chosen in order to promote the degradation of the polymers by the bacteria Pseudomonas aeruginosa. The PLA material was also compared in a solid agar supplemented with nutrient-rich medium. In Figure 3, are shown representative micrographs of the bacterial growth found on the surface of the coupons.
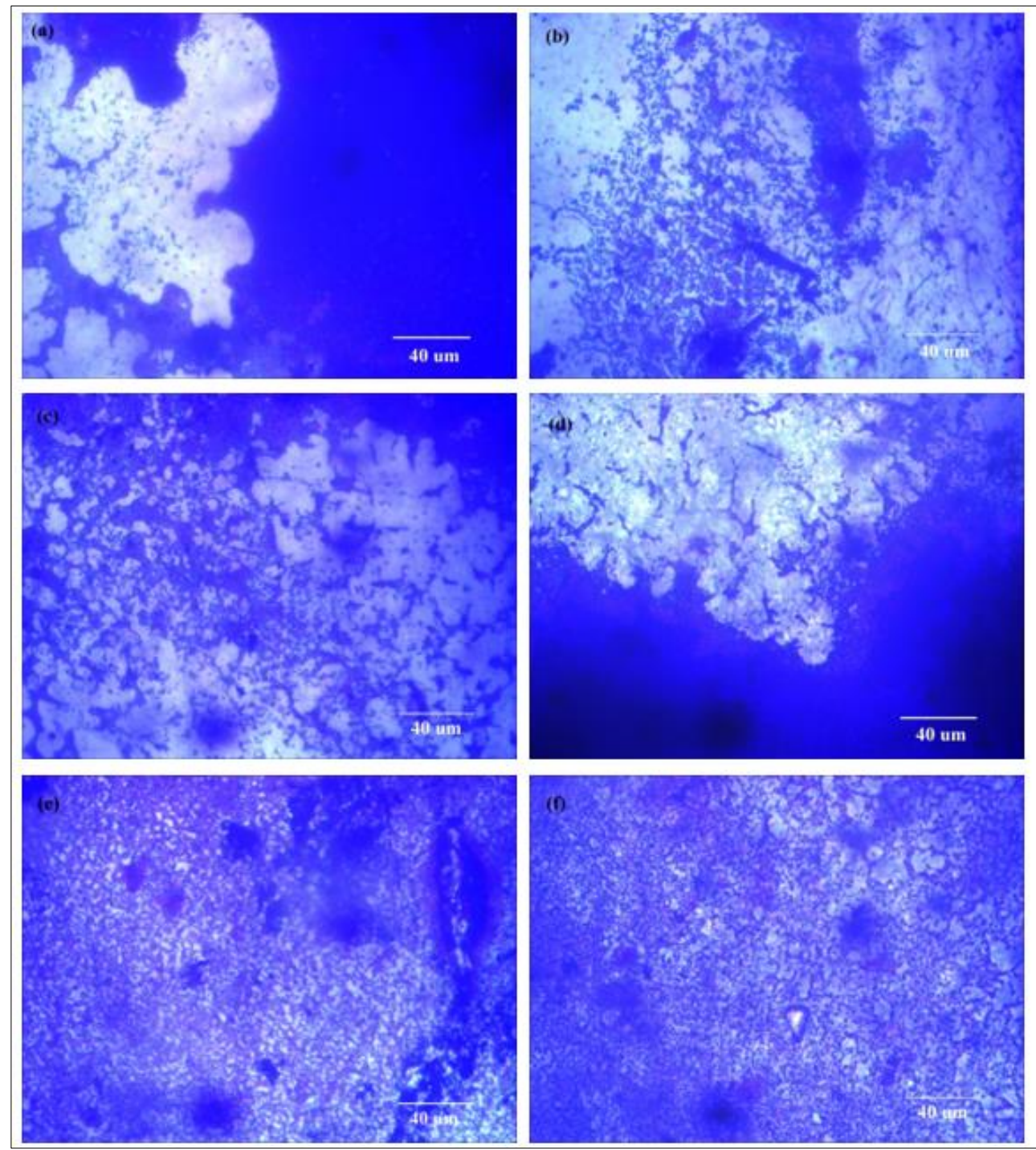

Figure 3. Micrograph of bacterial biofilms at the conditions of time (medium), material and coupon region: (a) $24 \mathrm{~h}$ (nutrient-low), nPLA, edge; (b) $48 \mathrm{~h}$ (nutrient-rich), PLA, center, (c) $72 \mathrm{~h}$ (nutrient-low), nPLA, center, (d) $168 \mathrm{~h}$ (nutrient-low), nPLA, edge,

(e) $168 \mathrm{~h}$ (nutrient-low), PLA, enter, (f) $336 \mathrm{~h}$ (nutrient-low), nPLA, center

The experiment was carried out for 14 consecutive days (lapses of 24, 48, 72, 168 and $336 \mathrm{~h}$ ). The formation of biofilm was evidenced in all the materials coupons and media (rich and low in nutrients). As shown in Figure 3, the bacterial growth structures are recognized because they were stained violet, due to the specific dye used. Likewise, it has been reported by other researchers that there are no differences in the count of colonies on agar plates emulsified with polycaprolactone or poly(hydroxy butyrate), comparing between nutritive or basal medium [17]. In some micrographs (Figure 3a, 3b, 3c), some individual bacteria were recognized by their elongated shape. Planes of different heights 
distinguished by the different intensities of the violet color in the biofilm were observed through the light microscope. This is a consequence of the three-dimensional and heterogeneous structures of the bacterial biofilms [22].

Considerable differences were noticed in the bacterial density between the micrograph taken at the center and at the edge of the coupons in all the materials and mediums, which can be seen in Figure 3. This occurred predominantly during the course of the first three evaluations (24, 48 and $72 \mathrm{~h}$ ). In the following measurements (168 and $336 \mathrm{~h}$ ) the bacterial density was more uniform along the coupons surface. The bacteria colonized the coupons from the edges to the center in all mediums (low and rich in nutrients) and materials (PLA and nPLA). It is considered that, given the arrangement of the coupons on the agar plate, this could generate an atmosphere with limited oxygen content under the polymer film, compared to the area coupon-free in the solid agar. The Pseudomonas aeruginosa is an aerobic specie of bacteria, therefore, what was supposed could explain the gradient of growth and colonization of bacteria from the edges of the coupon towards the center. However, this explanation is merely speculative.

The variation of the area occupied by the bacterial growth structures in function of the time, was calculated using the ImageJ software in the micrographs taken. In Figure 4, the percentage of area occupied by the biofilm in the coupons is presented. In the first $100 \mathrm{~h}$, there was a great variability in the structures and in the distribution of the biofilm along each material coupon, which caused the dispersion of results evidenced.

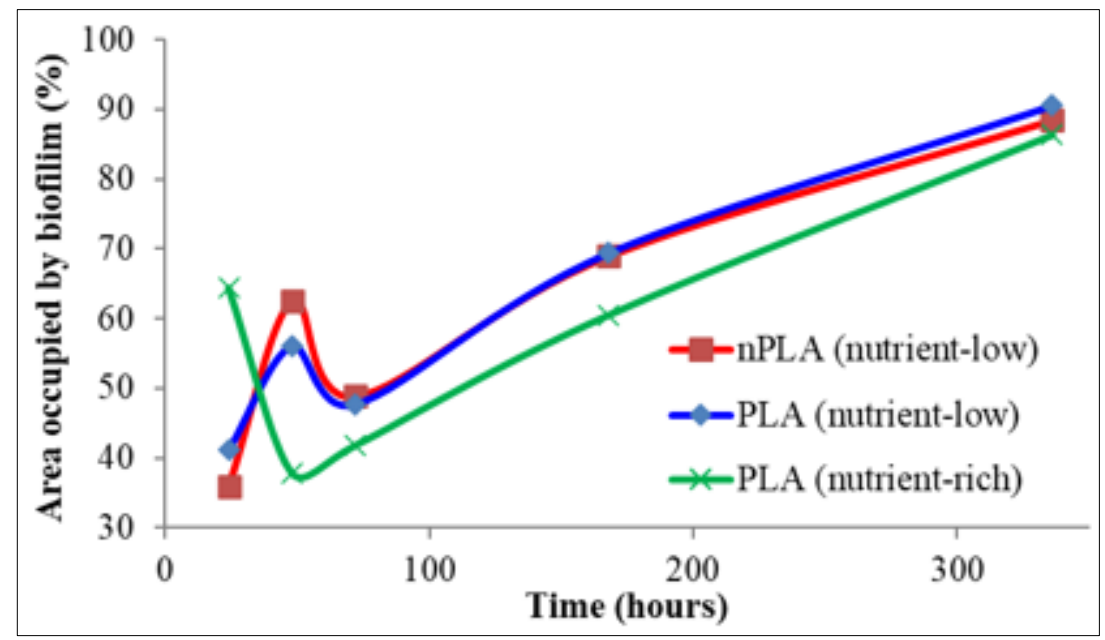

Figure 4. Area of the coupons (\%) occupied by the bacterial biofilm

The results shown in Figure 4 suggest that there were few differences in the area occupied by the biofilm between the different materials used and the two types of media. The nutrient-low medium was used in order to promote the degradation of the polymer film by the microorganisms, however it possessed glycerol at $0.1 \% \mathrm{v} / \mathrm{v}$, which could have been a source of nutrients during the two weeks. Therefore, the longest duration of these test (14 days) was still a very short period to detect complete biodegradation of the PLA and nPLA coupons. However, some investigations [22, 23] on biofilms formed in synthetic (or non-biodegradable) polymers, such as poly(vinyl chloride), polystyrene and poly(methyl methacrylate), registered biodeterioration on these polymers. Nonetheless, those studies were performed in a medium with composition similar to the one used in the present investigation but supplemented with glucose and amino acids $[22,23]$.

Due to the results of the first experimental setup, it was decided to perform a second setup with a liquid medium without glycerol and without nutrients in the PLA and nPLA coupons, for 30 days. For comparative purpose, some PLA coupons were placed on solid agar (low-nutrient medium) for 30 days. At this time, the area occupied by biofilms reached $90 \%$. In contrast, the area occupied by bacterial biofilms in the PLA and nPLA coupons immersed in the liquid medium, barely covered $15 \%$ and 50\%, respectively. These results somehow reflected the effect of bacterial adhesion in the formation of biofilms. 
Firstly, the adhesion of bacteria is not affected by the physical state of the medium, verified by Zameer et al. [16]. These researchers demonstrated that the adhesion capacity of Pseudomonas aeruginosa for biofilm formation in polystyrene, glass and steel, was not affected by the physical state of the medium. Secondly, the differences in the composition of the medium may partially explain the results since the solid medium contained glycerol as the only source of nutrients and the liquid medium was totally devoid of nutrients. The effect of the composition was studied by Fletcher et al. [18], who evaluated the formation of biofilms by four species of bacteria on polystyrene. They found remarkable differences in adhesion capacity depending on the composition of the medium, since bacteria react physiologically to fluctuations in the environment.

It should be remarked that, for the coupons immersed in the liquid medium, the biofilms and aggregates of bacteria grew and were found randomly. In the case of the nPLA coupons, structures similar to the biofilms found in the coupons placed on solid agar were observed after one month (Figure $5 b)$. In contrast, the PLA coupons did not show biofilm formation, however some dispersed aggregates of bacteria were confirmed as shown in Figure 5a. These morphological differences in the bacterial growth on PLA and nPLA materials in liquid medium can only be explained by the surface and topographic characteristics of both materials.

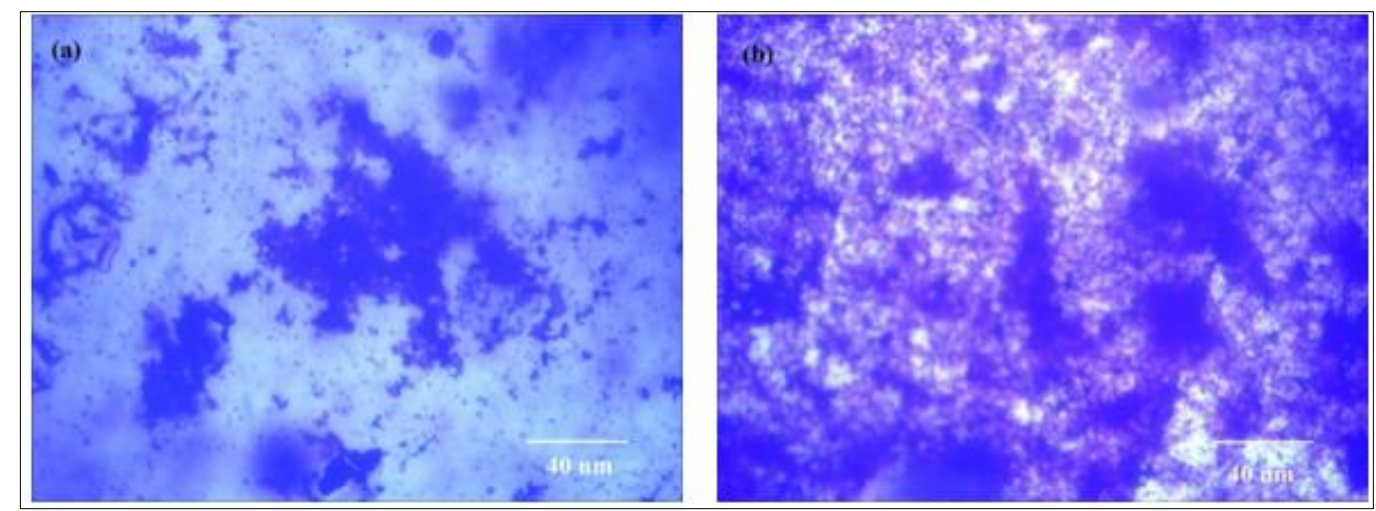

Figure 5. Micrographs of the bacterial growth and biofilms (after 30 days) formed in the coupons of (a) PLA and (b) nPLA, immersed in the liquid medium (nutrient-devoid)

The bacterial adhesion to a solid surface in an aqueous system involves complex interactions between the bacteria, the substrate, and the liquid medium. Adhesion is affected by the surface hydrophilicity due to the physical interactions between polar or non-polar groups presented on the substrate and on the surface of the bacteria [19] Therefore, the presence of sepiolite (hydrophilic clay) could modify this property in the nanocomposite film (nPLA) favoring the adhesion of microorganisms. Another factor to consider is the roughness of the solid surface on which the bacteria are fixed: the higher the roughness, the greater the surface area that favors adhesion mechanism [16]. In the case of the nanocomposite (nPLA) at the nanometric level, its surface has an irregular topography caused by the presence of the nanoparticles of clay (needles of sepiolite), possibly favoring the fixation of bacteria. Finally, the bacterial adhesion is dependent on attractive physical forces of short and long range (such as electrostatic forces, dipole interactions, Van der Waals forces) and chemical (such as hydrogen bonds) [18, 19]. Therefore the presence of the sepiolite chemical groups on the surface of the nanocomposite could contribute to some of these interactions, specifically the magnesium cations and silanol groups presented in its structure [21]. Summarizing, the presence of sepiolite nanoclay contributed to the bacterial adhesion of Pseudomonas aeruginosa possibly owing to its hydrophilic properties, the possible interactions between its surface chemical groups and the bacteria and the higher surface roughness originated in the nanocomposite (nPLA).

Some researchers have reported that PLA is a difficult polymer to biodegrade [1]. Unlike other biodegradable polyesters such as polycaprolactone, few species of bacteria are found in natural environments that show effective biodegradation of PLA. On the other hand, it has been reported that 
biodegradation requires a longer test time and the simultaneous use of various species of microorganisms [2]. Therefore, the most relevant result in this investigation was the viable growth of the bacteria Pseudomonas aeruginosa on the PLA and nPLA materials, in a liquid medium completely devoid of nutrient for 30 days. A greater area occupied by the bacterial biofilms were observed on the surface of the nanocomposite, probably due to the positive effects of the nanoclay on bacterial adhesion, explained by the differences in roughness, hydrophilicity and surface charge compared to the PLA polymer. However, the density of bacteria was higher in the first assembly (coupons on solid agar), possibly due to the availability of glycerol as an easily metabolizable nutrient.

\section{Conclusions}

The following conclusions are stated:

-the poly(lactic acid) nanocomposite with $5 \mathrm{wt} \%$ of sepiolite (nPLA) is a material with higher average values of the Young's modulus and tensile strength at break, increased by $20 \%$ and $8 \%$ respectively compared to the PLA, without detriment in the percent elongation at break;

-the growth of Pseudomonas aeruginosa on the PLA and nPLA materials was completely viable in a liquid medium totally nutrient-devoid for one month, where the nanocomposite presented a higher coverage of microorganisms on its surface, possibly due to the positive effects of the nanoclay on bacterial adhesion;

-the growth of Pseudomonas aeruginosa on films of PLA and nPLA materials occurred through biofilm formation, as a possible biodegradation mechanism.

\section{References}

1.JIMÉNEZ, A., PELTZER, M. A., RUSECKAITE, R. A. Poly(lactic Acid) Science and Technology: Processing, Properties, Additives and Applications, The Royal Society of Chemistry, Cambrige, 2015, 37-65. https://doi.org/10.1039/9781782624806.

2.AYRILMIS, N., YURTTAȘ, E., DURMUS, A., ÖZDEMIR, F., NAGARAJAN, R., KALIMUTHU M., KITEK KUZMAN, M. Properties of Biocomposite Films from PLA and Thermally Treated Wood Modified with Silver Nanoparticles Using Leaf Extracts of Oriental Sweetgum, J. Polym. Environ., 12, 2021, 1-14. https://doi.org/10.1007/s10924-021-02065-x.

3.FUKUSHIMA, K., FINA, A., GEOBALDO, F., VENTURELLO, A., CAMINO, G. Properties of Poly (Lactic Acid) Nanocomposites Based on Montmorillonite, Sepiolite and Zirconium Phosphonate, eXPRESS Polym. Lett., 6(11), 2012, 914-926. https://doi.org/10.3144/expresspolymlett.2012.97.

4.NUÑEZ, K., ROSALES, C., PERERA, R., VILlarREAL, N., PASTOR, J. M. Poly (Lactic Acid)/Low-Density Polyethylene Blends and Its Nanocomposites Based on Sepiolite, Polym. Eng. Sci., 52(5), 2012, 1-17. https://doi.org/10.1002/pen.22168.

5.FUKUSHIMA, K., TABUANI, D., CAMINO, G. Poly (Lactic Acid)/Clay Nanocomposites: Effect of Nature and Content of Clay on Morphology, Thermal and Thermo-Mechanical Properties, Mater. Sci. Eng., 32, 2012, 1790-1795. https://doi.org/10.1016/j.msec.2012.04.047.

6.SABZI, M., JIANG, L., ATAI, M., GHASEMI, I. PLA / Sepiolite and PLA / Calcium Carbonate Nanocomposites: A Comparison Study, J. Appl. Polym. Sci., 129(4), 1734-1744, 2013.

https://doi.org/10.1002/app.38866.

7.RUSSO, P., CAMMARANO, S., BILOTTI, E., PEIJS, T., CERRUTI, P., ACIERNO, D. Physical Properties of Poly Lactic Acid / Clay Nanocomposite Films: Effect of Filler Content and Annealing Treatment, J. Appl. Polym. Sci., 131(2), 2014, 1-8. https://doi.org/10.1002/app.39798.

8.NUÑEZ, K., ROSALES, C., PERERA, R., VILLARREAL, N., PASTOR, J. M. Nanocomposites of PLA/PP Blends Based on Sepiolite, Polym. Bull., 67, 2011, 1991-2016.

https://doi.org/10.1007/s00289-011-0616-7.

9.ROSALES, C., SABINO, M., PERERA, R., ROJAS, H. Effects of degradation during the processing on morphology and tensile properties of nanocomposites blends of poly (lacti acid) with polyethylene, Revista Técnica de la Facultad de Ingeniería Universidad del Zulia, 37(2), 2014, 135-143. 
http://ve.scielo.org/pdf/rtfiuz/v37n2/art05.pdf.

10.TAUBNER, V., SHISHOO, R. Influence of Processing Parameters on the Degradation of Poly(L Lactide) During Extrusion, J. Appl. Polym. Sci., 79, 2001, 2128-2135.

https://doi.org/10.1002/1097-4628(20010321)79:12<2128::AID-APP1020>3.0.CO;2-\%23

11.MOAZENI, M., MOHAMAD, Z., DEHBARI, N. Study of Silane Treatment on Poly-Lactic acid(PLA)sepiolite Nanocomposite Thin Films. J. Appl. Polym. Sci., 41428, 2014, 1-8.

https://doi.org/10.1002/app.41428.

12.LIU, M., PU, M., MA, H. Preparation, Structure and Thermal Properties of Polylactide/sepiolite Nanocomposites with and without Organic Modifiers., Compos. Sci. Technol., 72(13), 2012, 1508-1514. https://doi.org/10.1016/j.compscitech.2012.05.017.

13.GARCÍA, L., CASTELL, P., PEINADO, V., MUNIESA, M., FERNANDEZ, A. Improvement of Mechanical Properties of Poly(Lactic Acid) by Integration of Sepiolite Nanoclays: Effect of Ultrasonication on Clay Dispersion, Materials Research Innovations, 18(2), 2014, 1-6.

https://doi.org/10.1179/1432891714Z.000000000386

14.FUKUSHIMA, K., TABUANI, D., ABBATE, C., ARENA, M., FERRERI, L. Effect of Sepiolite on the Biodegradation of Poly(lactic Acid) and Polycaprolactone, Polym. Degrad. Stab., 95(10), 2010, 2049-2056. https://doi.org/10.1016/j.polymdegradstab.2010.07.004

15.WALCZAK, M., BRZEZINSKA, M. S., SIONKOWSKA, A., MICHALSKA, M., JANKIEWICZ, U., DEJA-SIKORA, E. Biofilm Formation on the Surface of Polylactide during Its Biodegradation in Different Environments, Colloids Surfaces B Biointerfaces, 136, 2015, 340-345.

https://doi.org/10.1016/j.colsurfb.2015.09.036.

16.ZAMEER, F., RUKMANGADA, M. S., CHAUHAN, J. B., KHANUM, S. A., KUMAR, P., DEVI, A. T., NAGENDRA PRASAD, M. N., DHANANJAYA, B. L. Evaluation of Adhesive and AntiAdhesive Properties of Pseudomonas Aeruginosa Biofilms and Their Inhibition by Herbal Plants, Iran. J. Microbiol., 8(2), 2016, 108-119.

https://www.ncbi.nlm.nih.gov/pmc/articles/PMC4906717/pdf/IJM-8-108.pdf.

17.NISHIDA, H., TOKIWA, Y. Distribution of Poly(B-Hydroxybutyrate) and Poly(E-Caprolactone) Aerobic Degrading Microorganisms in Different Environments, J. Environ. Polym. Degrad., 1(3), 1993, 227-233. https://doi.org/10.1007/BF01458031.

18.MCELDOWNEY, S., FLETCHER, M. Effect of Growth Conditions and Surface Characteristics of Aquatic Bacteria on Their Attachment to Solid Surfaces, Microbiol., 132(5), 513-523, 1986.

https://doi.org/10.1099/00221287-132-2-513

19.KOUBALI, H., EL LOUALI, M., ZAHIR, H., SOUFIANI, S., MABROUKI, M., LATRACHE, H. Physicochemical characterization of glass and polyethylene surfaces treated with different surfactants and their effects on bacterial adhesion. Int. J. Adhes. Adhes., 104, 2021, 102754.

https://doi.org/10.1016/j.ijadhadh.2020.102754.

20.***Technical Datasheet PLA NatureWorks ${ }^{\circledR}$ Ingeo TM. Link:

http://matweb.com/search/DataSheet.aspx?MatGUID=1e288619764846d2b794bd077e7f1bba\&ckck=1

Data: December 20-2020.

21.***Technical Datasheet Sepiolita. Link:

http://www.webmineral.com/data/Sepiolite.shtml\#.WFcuSvnhDIU. Data: January 05-2021.

22.KASTENHOFER, J., RAJAMANICKAM, V., LIBISELLER-EGGER, J., SPADIUT, O. Monitoring and control of E. coli cell integrity, J. Biotechnol., 329, 2021, 1-12.

https://doi.org/10.1016/j.jbiotec.2021.01.009.

23.O'TOOLE, G. A., KOLTER, R. Initiation of Biofilm Formation in Pseudomonas Fluorescens WCS365 Proceeds via Multiple, Convergent Signalling Pathways: A Genetic Analysis, Mol. Microbiol., 28(3), 1998, 449-461. https://doi.org/10.1046/j.1365-2958.1998.00797.x.

Manuscript received: 15.03 .2021 